\title{
A Simple Method to Obtain the Mycococcus Form of Mycobacterium phlei
}

\author{
By ANNA CSILLAG \\ Medical Research Council's Unit for Laboratory Studies of Tuberculosis, \\ Royal Postgraduate Medical School, London W.I2
}

(Accepted for publication I May 1970)

\begin{abstract}
SUMMARY
A method for the isolation of mycococci directly from cultures of $\mathrm{Myco}$ bacterium phlei is described. The method consists of the cultivation of $M$. phlei in Middlebrook's $7 \mathrm{H} 9$ liquid medium without the addition of any enrichments. The medium was distributed in screw-capped bottles, plugged for 3 weeks with cotton-wool only and then for another 4 weeks with the caps screwed on top of the cotton-wool plugs. The mycococci were then isolated on subcultures on nutrient agar. A streptomycin-resistant variant of $M$. phlei yielded a mycococcus that was streptomycin-resistant. Frequent subcultivation of the parent strain probably prevented the development of mycococci. Evidence is submitted that the mycococci were not contaminants.
\end{abstract}

\section{INTRODUCTION}

Evidence has been reported previously that strains of rapidly growing, sporeforming organisms which were not acid-fast could be isolated from cultures of mycobacteria, including Mycobacterium tuberculosis (Csillag, I96 I, I962, 1963a, $b$, 1964a, b). Mycobacteria might therefore be considered as dimorphic organisms in the same sense as are some pathogenic fungi, for instance, Histoplasma capsulatum. The usual acidfast form of the mycobacteria was termed 'form I' and the form which was not acidfast was termed 'form 2'. When grown on nutrient agar, the form 2 strains resembled species of the genus Bacillus (Csillag, 196I). However, in slide culture they showed characteristics similar to, but not identical with, some species of the genus Nocardia, particularly, pseudobranching and fragmentation into bacillary and coccoid elements (Csillag, 1963a). The classification of form 2 strains could not be completed, since the appearance of endospores excluded the possibility of classification with the family Actinomycetaceae, but fragmentation of pseudobranching filaments into coccoid elements rendered the classification among the Bacillaceae untenable (Csillag, 1963a). Furthermore, when grown in digest broth, form 2 strains produced cocci which continued to multiply by binary fission and bud formation and were identified as species of the genus Mycococcus (Csillag, 1964b). Stewart-Tull (1965) also reported the isolation of form 2 mycobacteria and mycococci from $M$. phlei.

There has been considerable variation in the ease with which form 2 strains were isolated from the form I mycobacteria, and mycococci from the form 2 strains. Although the precise conditions which favour these changes are not known, it is likely that repeated subculture of form I strains leads to their 'stabilization', in which state they are unlikely to yield form 2 isolates (Csillag, I963 $b$ ). Similarly, frequent subcultivation 
of form 2 strains prevented the isolation of mycococci (Csillag, $1964 b$ ). In the process of stabilization of the form 2 strains, not only did it become more difficult to isolate mycococci but the resemblance between the form 2 strains and bacilli became greater. In particular, form 2 organisms, which appeared frankly Gram-negative when first obtained from form I strains, were Gram-variable or Gram-positive when stabilized, and the Nocardia-like appearances in slide culture could no longer be obtained (Csillag, $1963 b$ ). Thus fully stabilized form 2 strains appeared identical to species of the genus Bacillus. It is therefore not surprising that Hilson (1965) identified form 2 strains, including two obtained from the author, as $B$. licheniformis. However, one of the strains that he had isolated from Mycobacterium tuberculosis was later shown by the present author to produce mycococci, and cannot therefore be considered as a bacillus, irrespective of other similarities. Hilson did not examine any of the form 2 strains for the production of mycococci; thus his identification was incomplete because production of mycococci is the most striking characteristic of form 2 mycobacteria.

Hilson's argument was that form 2 mycobacteria derive from contamination of mycobacteria with the spores of a Bacillus species (Hilson, 1965). Controls included in the earlier experiments strongly suggested that this was not the case (Csillag, I96I). However, since it is difficult to provide completely convincing evidence, a method has been developed for the isolation of mycococci directly from cultures of mycobacteria, thus avoiding the appearance of the spore-bearing form 2 strains. Chance contamination of the cultures with mycococci is inherently much less probable, since these organisms are rarely found as laboratory contaminants and, as they do not produce spores, it is easier to be certain that sterilization of media has been completely effective. This method is described in the present report, together with experiments in which the transmission of streptomycin sensitivity or resistance from the parent form I strains to the mycococci isolated was followed.

\section{METHODS}

Strains of Mycobacterium phlei. Strains NCTC8I5I and NCTC8I56 were obtained freeze-dried from the National Collection of Type Cultures. Strain S-T was obtained as a fluid medium culture from Dr Stewart-Tull, Glasgow University.

Media. (I) Nutrient agar plates were made by the addition of $1 \cdot 3 \%(\mathrm{w} / \mathrm{v})$ Oxoid no. 3 agar to Oxoid no. 2 broth (Oxo Ltd, London). (2) Oxoid no. 2 nutrient broth. (3) Martin's digest broth ( $A$ System of Bacteriology, I93I). (4) Yeast extract, Oxoid

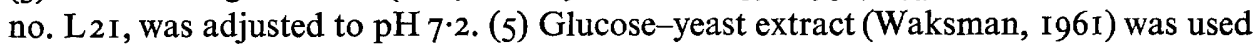
without agar. (6) Lab-Lemco beef extract, Oxoid no. $\mathrm{L}_{30}$, with the $\mathrm{pH}$ adjusted to $7 \cdot 4$, was used in various concentrations with or without the addition of other ingredients. (7) Middlebrook's $7 \mathrm{H}_{9}$ broth was prepared by rehydrating the dehydrated medium (Difco Laboratories, Detroit, Michigan, U.S.A.) without the addition of glucose, glycerol, Tween 80 , albumin or catalase. The medium was adjusted to $\mathrm{pH} 6 \cdot 6$. The nutrient agar plates were incubated, sealed in a polythene bag at $37^{\circ}$ for 7 days before use, as a sterility test. The liquid media were distributed in $8 \mathrm{ml}$. amounts in $\frac{1}{2} \mathrm{oz}$ screw-capped bottles. The bottles were plugged with firmly rolled cotton-wool, then autoclaved at $15 \mathrm{lb}$./in. ${ }^{2}$ for $\mathrm{I} 5 \mathrm{~min}$., incubated at $37^{\circ}$ for 3 days and then re-autoclaved. A sterility test was carried out at $37^{\circ}$ for 7 days.

Isolation of cocci from cultures of Mycobacterium phlei. Cocci were obtained from $M$. phlei as follows. The strains of $M$. phlei were purified three times by single colony 
selection on nutrient agar plates. After incubation for 7 days, 60 large ( 4 to $5 \mathrm{~mm}$. diam.) colonies from the third set of plates ('starter cultures') were marked. About $2 \mathrm{mg}$. moist weight was taken by loop from half of each of these colonies and inoculated into a bottle of the fluid medium ('test cultures'). The 60 test cultures were incubated with plugs but without screw-caps for 3 weeks. Sterile caps were then screwed on. The bottles were moved as little as possible to avoid disturbance of the sediment. Twice a week two of the test cultures were investigated and then discarded. Investigation was done by removing with a Pasteur pipette macroscopically visible floccules (or mucoid material, if present) from the undisturbed sediment. The floccules were stained by Jensen's modification of the Gram method or by the Ziehl-Neelsen method (Cruickshank, I965), and the remainder was plated out on four nutrient agar plates ('subculture from test cultures'). These plates were incubated for 8 days, after which all colonies that differed from the original colonies of $M$. phlei were isolated and kept for further identification. All cultures were incubated in a moist incubator at $37^{\circ}$. All work was carried out in an armhole cabinet previously irradiated for $30 \mathrm{~min}$. with ultraviolet radiation.

Isolation of cocci from streptomycin-resistant variant of Mycobacterium phlei. The minimal inhibitory concentration (m.i.c.) of streptomycin for strain 8I5I was less than $\mathrm{I} \cdot 75 \mu \mathrm{g} . / \mathrm{ml}$. A streptomycin-resistant variant of this strain was prepared by single-step selection on nutrient agar plates containing $1000 \mu \mathrm{g} . / \mathrm{ml}$. streptomycin. The colonies were plated on streptomycin-free and streptomycin-containing medium to be sure that they were resistant to, but not dependent on, streptomycin. One of these colonies was purified three times on nutrient agar plates containing $1000 \mu \mathrm{g} . / \mathrm{ml}$. streptomycin and was then used as a 'starter culture' in an experiment to produce cocci, as described above. In this experiment, $7 \mathrm{H}_{9}$ medium was used.

Controls. The following controls were included in all of the 44 experiments. (I) Inoculum controls: the remaining halves of each of the 60 colonies on the starter plates were plated out on nutrient agar. The plates were sealed with a double layer of Parafilm (Gallenkamp, London) and were incubated at $37^{\circ}$ until the end of the experiments. (2) Contamination controls: 60 bottles of the same batch of media used for the test cultures were 'inoculated' with a sterile loop and were incubated exactly as the test cultures until the end of the experiment, when they were plated out on nutrient agar and incubated for 14 days.

Reconstruction experiments. Reconstruction experiments were carried out with strain 8I5I to see whether the growth of small numbers of mycococci was influenced by the presence of large numbers of Mycobacterium phlei. Serial tenfold dilutions of a well-shaken 4-day-old culture of the recently isolated mycococcus were prepared. From each of the dilutions, $0.02 \mathrm{ml}$. amounts were inoculated into bottles of $7 \mathrm{H}_{9}$ medium without or with a heavy (about $2 \mathrm{mg}$. moist weight) inoculum of $M$. phlei, and were also plated out on nutrient agar. The colonies on the agar plates were counted after incubation for 5 days. The fluid medium cultures were incubated for 5 days and then $0.02 \mathrm{ml}$. amounts of the undisturbed sediment were plated out and the plates were incubated for 5 days. The colonies were then counted.

Identification of the cocci. Identification of the cocci started immediately after their isolation, without previously passaging the strains. 


\section{RESULTS}

Results of the 38 preliminary experiments. In these experiments, all three strains of Mycobacterium phlei and nine different media were tested (Table I, Expts. I to 38). All experiments were terminated after incubation of the test cultures for 52 weeks. Strain 8156 yielded mycococci in seven cultures in $0.3 \%$ Lab-Lemco medium. No cocci were isolated in the remainder of the experiments.

Table I. Development of mycococci in cultures of Mycobacterium phlei

\begin{tabular}{|c|c|c|c|c|c|c|c|}
\hline \multirow[b]{2}{*}{$\begin{array}{c}\text { Expt. } \\
\text { no. }\end{array}$} & \multirow[b]{2}{*}{$\begin{array}{l}\text { Strains } \\
\text { of } \\
M . \text { phlei }\end{array}$} & \multirow{2}{*}{$\begin{array}{l}\text { No. of } \\
\text { previous } \\
\text { passages } \\
\text { of starter } \\
\text { cultures }\end{array}$} & \multirow[b]{2}{*}{ Medium } & \multicolumn{2}{|c|}{$\begin{array}{l}\text { No. of test } \\
\text { cultures }\end{array}$} & \multicolumn{2}{|c|}{ Weeks } \\
\hline & & & & Set up & $\begin{array}{c}\text { Yielding } \\
\text { cocci }\end{array}$ & $\begin{array}{c}\text { Cocci } \\
\text { first } \\
\text { isolated }\end{array}$ & $\begin{array}{c}\text { Duration } \\
\text { of } \\
\text { expt. }\end{array}$ \\
\hline I-29 & $\begin{array}{l}\text { NCTC 8I II } \\
\text { NCTC 8I } 56 \\
\text { S-T }\end{array}$ & $\begin{array}{l}\text { Varied } \\
\text { between } \\
\text { o and } 52\end{array}$ & Various* & $\left\{\begin{array}{l}60 \\
60 \\
60\end{array}\right\}$ & 0 & - & 52 \\
\hline 30 & NCTC 8I5I & 0 & $0.1 \% \mathrm{~L}-\mathrm{L}+$ & 60 & 0 & - & 52 \\
\hline $3 \mathrm{I}$ & NCTC 8156 & 0 & $0.1 \%$ L-L & 60 & 0 & - & 52 \\
\hline 32 & $S-T$ & c. 50 & $0.1 \% \mathrm{~L}-\mathrm{L}$ & 60 & 0 & 一 & 52 \\
\hline 33 & NCTC 8I $5 I$ & 0 & $0.3 \%$ L-L & 60 & 0 & - & 52 \\
\hline 34 & NCTC 8156 & 0 & $0.3 \%$ L-L & 60 & 7 & 52 & 52 \\
\hline 35 & S-T & c. 50 & $0.3 \%$ L-L & 60 & 0 & - & 52 \\
\hline 36 & NCTC 8I 5 I & 0 & $1.0 \% \mathrm{~L}-\mathrm{L}$ & 60 & 0 & - & 52 \\
\hline 37 & NCTC 8156 & 0 & $1 \cdot 0 \%$ L-L & 60 & 0 & - & 52 \\
\hline 38 & S-T & c. 50 & $1.0 \%$ L-L & 60 & 0 & 一 & 52 \\
\hline 39 & NCTC 815 I & 0 & $7 \mathrm{H}_{9}$ & 60 & 33 & 7 & 7 \\
\hline 40 & NCTC 8I 5 I & 3 & $7 \mathrm{H}_{9}$ & 60 & 30 & 8 & 30 \\
\hline $4 \mathrm{I}$ & NCTC 8I 51 & 24 & $7 \mathrm{H}_{9}$ & 60 & I & 16 & 30 \\
\hline 42 & NCTC $8151 \ddagger$ & 24 & $7 \mathrm{H} 9$ & 60 & 4 & 10 & 16 \\
\hline 43 & NCTC 8156 & 0 & $7 \mathrm{H}_{9}$ & 60 & 5 & I8 & 52 \\
\hline 44 & S-T & c. 60 & $7 \mathrm{H}_{9}$ & 60 & 0 & - & 52 \\
\hline
\end{tabular}

* Nutrient broth, Martin's digest broth, yeast extract, glucose-yeast extract, $0.3 \%$ Lab-Lemco beef extract with $0.3 \mu \mathrm{g} . / \mathrm{ml}$. streptomycin or $0.1 \%$ saponin.

$\dagger$ Lab-Lemco.

\$ Streptomycin-resistant variant.

Origin of cocci from Mycobacterium phlei. Since experiment 39 (Table I) yielded the largest number of isolates of mycococci, detailed results of that experiment only are presented:

I. Macroscopic appearance of the test cultures. After incubation for I week, the medium of the test cultures was clear, with a thin surface pellicle and a small amount of floccular sediment. Within 3 weeks the pellicle sedimented and no new one formed during the experiment. The medium was clear throughout, but most of it evaporated and at the time the caps were screwed on, about $3 \mathrm{ml}$. medium was left. After incubation for 6 weeks, the sediment in some bottles became slightly mucoid, and at the end of the seventh week the sediment of all but three of the remaining cultures was very mucoid.

2. Microscopic appearance of the sediment in the test cultures. In smears stained by the Ziehl-Neelsen stain, the rods were strongly acid-fast for a week, then started to lose acid-fastness gradually until the end of the third week acid-fastness was only observed occasionally. Since little information had been gathered on the poorly counter- 
stained rods, this staining method was not used after the fourth week. At the end of the first week the protoplasm of the rods stained evenly Gram-positive; later, in an increasing proportion of the rods, strongly Gram-positive granules were seen while the rest of the protoplasm stained lighter blue. At the end of the third week some of the granules appeared to be liberated from the rods. The free granules were strongly Gram-positive and were circular or irregular, ranging in diameter from 0.1 to $0.5 \mu \mathrm{m}$. At the end of the seventh week only free granules ( 0.1 to $0.8 \mu \mathrm{m}$ ) and very short rods were seen. In the three cultures which were not mucoid, the granules were lying singly, but in the 33 mucoid cultures, they were seen in the process of multiplication by fission; thus they should be regarded as cocci. The cocci were strongly Gram-positive and were arranged singly, in pairs or in short chains. Some divided in two planes, giving rise to tetrad-like configurations.

3. Subculture of the test cultures. Those test cultures which had been incubated for up to 6 weeks ( 24 cultures) and those three cultures whose deposit was not mucoid at the seventh week yielded on nutrient agar only the original colonies of Mycobacterium phlei which were composed of the original acid-fast rods only. However, by the end of the seventh week the 33 mucoid cultures yielded, in addition to the original colonies, at least 20 colonies of an additional type. At I day these were circular, pale yellow, variable in size $(0.2$ to $0.8 \mathrm{~mm}$. diam.) and had a smooth surface. During the next I4 days their size increased $(2.0$ to $6.0 \mathrm{~mm}$. diam.) and the surface became rather wrinkled or folded. The colonies were composed of Gram-positive cocci, the main feature of which was their difference in shape and size. No other organisms were observed on any of the plates.

Reproducibility of Expt. 39. Expt. 39 has been repeated twice, using the same method except that, prior to the experiments, the starter culture was subcultivated 3 times in Expt. 40 and 24 times in Expt. 4I (Table I). In Expt. 40, out of the 60 test cultures 30 yielded cocci, but in Expt. 4I cocci were isolated from only a single culture.

Isolation of cocci from the streptomycin-resistant Mycobacterium phlei. In this experiment the streptomycin-resistant starter culture was subcultivated 24 times prior to the experiment. Of the 60 test cultures, four yielded mycococci (Table I, Expt. 42). All cocci were resistant to $1000 \mu \mathrm{g}$. $/ \mathrm{ml}$. streptomycin. Mycococci obtained from the sensitive parent strain had an m.i.c. of about $\mathrm{r} \cdot 75 \mu \mathrm{g}$./ml. Although transfer of resistance from streptomycin-resistant $M$. phlei to streptomycin-sensitive cocci was not expected, the organisms were cultivated together in a separate experiment for 5 weeks. All cocci remained streptomycin-sensitive.

Reproduction of Expt. 39 with strains 8156 and S-T. Expt. 39 has been repeated with strains $8 \mathrm{I} 56$ and S-T. The starter culture of strain 8156 had not been subcultivated prior to the experiment, while the starter culture of strain S-T had been subcultivated about 60 times. Strain 8156 yielded cocci in 5 out of 60 bottles, while no cocci were obtained from strain S-T (Table I, Expts. 43, 44).

Results of the reconstruction experiments. The following mean numbers of colonies were obtained from the various dilutions of the mycococcus culture. Innumerable colonies from dilutions up to $1 \mathrm{I}^{-5}, 90$ colonies from the $\mathrm{IO}^{-6}$ dilution, 3 colonies from the $10^{-7}$ dilutions, no colonies from the remaining dilutions except for two colonies on one of the three plates from the $10^{-9}$ dilution. Heavy growth of cocci confirmed by subculture was obtained in the pure cultures as well as in the cultures mixed with Mycobacterium phlei in those bottles which were inoculated with cocci from dilutions 
up to $10^{-7}$, but no growth with higher dilutions occurred. In addition, innumerable colonies of $M$. phlei appeared on the agar plates inoculated with the mixed cultures.

Results of the controls. The inoculum controls yielded the original colonies of $M y c o-$ bacterium phlei only. The plates inoculated with the contamination controls remained sterile.

Identification of the cocci. The colonial and cellular morphology of the cocci were studied after their incubation for 14 days on nutrient agar plates and in nutrient broth. Prolonged incubation was necessary since long incubation is needed to reveal the true nature of mycococci, that is, to develop those characteristics which enable cells to be distinguished from those of the micrococci (Krassilnikov, 1934). All cocci isolated from the same strain had similar characteristics to each other and were similar generally to those isolated from other mycobacteria (Csillag, 1964b), though individual variations have been observed. After more than 5 or 6 subcultures, the cocci tended to die out. On the basis of their morphology, the cocci were identified as organisms belonging to the genus Mycococcus, family Mycobacteriaceae, order Actinomycetales (Bergey's Manual, 1957). No attempt has been made to identify the species.

\section{DISCUSSION}

Evidence that the mycococci were derived from Mycobacterium phlei and were not contaminants can be found in the following observations. (I) The mycococci were not present in the media. The media were autoclaved in such a way that even spore-bearing bacilli would have died, and all 'sterile control' media remained so until the end of the experiments. (2) The cocci were not present in the starter cultures; these were purified 3 times, and it is highly unlikely that cocci would be present within many colonies of $M$. phlei without forming a single colony on their own. Moreover, the second half of each of the starter colonies was plated out on to nutrient agar, and no colonies of cocci were produced on them until the end of the experiments (often 52 weeks). Finally, it was shown that even a few cells of cocci were capable of multiplying rapidly in the presence of large numbers of $M$. phlei. Thus, had the cocci been present in the inocula they would have multiplied at least in some of the younger test cultures. (3) It is most unlikely that identical mycococci gained access to several bottles of test cultures during inoculation while leaving uncontaminated all of the sterile controls. (4) It would be very surprising indeed if streptomycin-sensitive strains of $M$. phlei became contaminated with streptomycin-sensitive mycococci, and streptomycinresistant cultures of $M$. phlei selectively attracted streptomycin-resistant mycococci as contaminants. (5) Mycococci were found to be capable of good growth in the absence of $M$. phlei. Thus it cannot be postulated that the sterile controls remained sterile only because contaminatory cocci could not grow in them in the absence of $M$. phlei.

Considering the evidence listed above, it is reasonable to conclude that the mycococci were derived from the strains of Mycobacterium phlei. The serial examinations of smears taken from the test cultures suggested that cocci originated from the intracellular granules of the rods. After their liberation, the granules reached the size of a coccus in a few weeks, but their independent multiplication was preceded in some of the experiments by several months of a resting period. Only at the stage of independent multiplication were the cocci able to produce colonies on subculture. It is not known why the apparently fully developed cocci often needed such a long resting period before 
multiplication commenced, while in some soil mycobacteria the development of cocci is so rapid that within 2 days the initial rod phase is already over and only cocci are present (Krassilnikov, I934).

Certainly, there are many factors which promote or prevent the development of mycococci from mycobacteria, but so far only three have been observed. (I) The number of cultures yielding mycococci rapidly decreased when the starter cultures were frequently subcultivated prior to the experiments (Table I, Expts. 39 to $4 \mathrm{I}$ ). It is probable that subcultivation shortly before freeze-drying matters. This supposition could explain the observation that mycococci were obtained from 33 test cultures of strain NCTC 8I5I but from only five test cultures of strain 8I56, although both strains were set up in identical experiments immediately after their revival and purification (Table I, Expts. 39, 43). (2) Earlier authors have reported that the development of mycococci is most likely in cultures of mycobacteria grown under unfavourable conditions in media poor in nutrients (reviewed by Csillag, 1964b). The present series of experiments suggest that an abundance of available carbon and nitrogen decreases the chances of development of mycococci. No mycococci were produced by mycobacteria grown in rich media such as nutrient broth, Martin's digest broth, yeast extract, glucose-yeast extract and Lab-Lemco beef extract in a $\mathrm{I} \cdot 0 \%$ concentration (Table I, Expts. I to 29, 36 to 38). One strain yielded mycococci in 0.3\% Lab-Lemco (Table I, Expt. 34). This medium must be regarded as rather poor since scanty growth was obtained in it and no growth occurred in $0.1 \%$ Lab-Lemco. Good results were only obtained in $7 \mathrm{H}_{9}$ basic medium where the only sources of carbon were glutamate and citrate, and sources of nitrogen were glutamate and ammonium Tepper (1965) obtained poor growth in a similar basic medium supplemented with glucose. (3) It was always in the undisturbed sediment of cultures of mycobacteria that the mycococci developed. In Expt. 39 (Table I) many more cultures were included, some of which were shaken either intermittently or continuously and some were cultivated in bottles filled with the medium and with the caps screwed on at the very beginning. Mycococci were not obtained in any of these cultures, probably due either to too much or to too little oxygen being available. However suggestive these results are, many more are needed before any conclusion can be drawn.

The acid-fast rod form and the coccus form of Mycobacterium phlei are undoubtedly very different, but this fact does not disprove their origin from each other. Rather, it suggests that during the life-cycle of mycobacteria, which are higher organisms than the Eubacteriales, large groups of genes can be switched on or off by repressors, and that cell differentiation occurs. Considering even higher organisms, Histoplasma capsulatum exhibits clear differentiation into a simple budding yeast form, and a complex mould form, the latter producing conidiospores as well as thick-walled chlamidospores (Howard, I962). While the mould form has a simple nutritional requirement, the yeast is fastidious, requiring cysteine, biotin and thiamin for growth. In addition to these differences, Kobayashi \& Guiliacci (1967) observed dissimilarity in the chemical structure of the two forms; in particular, the amino-acid determination revealed not only quantitative but qualitative differences. According to Austwick (1968), the great variety in all of the dimorphic fungi is due to their very efficient genetic system which helps them to adapt very easily to different conditions in life. The same might well be the case with the mycobacteria. Thus form I corresponds to the yeast form, being morphologically simple and nutritionally fastidious, and form 2 corresponds to the mould 
form, having modest nutritional requirements and forming thick-walled endospores. The third form of mycobacteria (mycococcus) are regarded as 'degraded forms of mycobacteria' by Krassilnikov (1959), who first described these organisms (Krassilnikov, 1938). In the author's experiments, mycococci were obtained from both form I and form 2 mycobacteria under unfavourable conditions, but they tended to die out rapidly. Mycococci can sometimes be reverted to the acid-fast rods (Krassilnikov, I959; Juhasz, I962), but more often only a tendency towards reversion has been found in the appearance in old cultures of mycococci of occasional rods which were not acid-fast (Demikhovskii, 196I) or were acid-fast (Csillag, 1964b). More recently, Pease (1970) found that several Gram-positive cocci (mycococci) produced small bacteria that were variably acid-fast. Undoubtedly, it is easier to convert mycobacteria to mycococci than in the reverse direction, but considering the poor viability of mycococci this is not very surprising.

As explained above, the relationship between form $\mathrm{r}$, form 2 mycobacteria and mycococci can be explained by analogy to the dimorphic fungi. However, the similarity of form 2 mycobacteria to members of the genus Bacillus is surprising since form $\mathrm{I}$ mycobacteria and mycococci are classified within the order Actinomycetales and Bacillaceae in the order Eubacteriales (Bergey's Manual, 1957). Nevertheless, Bacillaceae have at least three striking characters which are seldom if ever seen in the remainder of the Eubacteriales but are common in one or more members of the Actinomycetales:

I. Type of growth. On solid medium most Bacillaceae have colonies with wrinkled, worm-cast surface and a tendency to crumble when touched with a loop and in stationary liquid-medium form a surface pellicle and a sediment, leaving the medium clear. Furthermore, in very young microcolonies of some bacilli, formation of initial filaments is seen followed later by their fragmentation and by further multiplication of these fragments by binary fission (Krassilnikov, 1959).

2. Acid-fastness. The spores of Bacillaceae resist decolorization with weak acids and alcohol and are thus potentially acid-fast (Topley \& Wilson, I964).

3. Spore formation. Members of the family Bacillaceae form endospores. Formation of any type of spores is unique for bacilli among members of the order Eubacteriales, whereas almost all members of the order Actinomycetales form some sort of spores (conidia, arthrospores, chlamidospores) (Waksman, 1959). Mycobacteria are generally regarded as organisms without spore formation, but genuine endospore-like structures have been repeatedly observed in different cultures of mycobacteria (Lack \& Tanner, I953; Xalabarder, 1954, 1958; Brieger \& Glauert, 1956). Considering these three characters of bacilli, it is probable that they should be classified closer to the Actinomycetales than to the Eubacteriales.

I wish to express my sincere thanks to Professor D. A. Mitchison for his very valuable suggestions. Thanks are due to $\mathrm{Mr} \mathrm{B}$. Allen for his conscientious technical assistance. 


\section{REFERENCES}

A System of Bacteriology in Relation to Medicine (193I), vol. 9, p. 60. Edited by the Medical Research Council. London: H.M. Stationery Office.

Austwick, P. K. C. (1968). Polymorphism in fungi. Journal of General Microbiology 50 , xv.

Bergey's Manual of Determinative Bacteriology (1957), 7th edn, pp. 707-771. Edited by R. S. Breed, E. G. Murray and N. R. Smith. Baltimore: Williams and Wilkins.

Brieger, E. M. \& Glauert, A. M. (1956). Spore-like structures in the tubercle bacillus. Nature, London 178, 544-545.

Cruickshank, R. (I965). Medical Microbiology, I Ith edn, pp. 649, 652. Edinburgh: E. and S. Livingstone.

CsillaG, A. (1961). Spore formation and 'dimorphism' in the mycobacteria. Journal of General Microbiology 26, 97-109.

CsillaG, A. (1962). Development of form 2 mycobacteria on autoclaved Loewenstein-Jensen medium. Tubercle, London 43, 439-443.

Csillag, A. (1963a). Cellular morphology of form 2 mycobacteria in slide culture. Journal of General Microbiology 30, $21-27$.

CsILlaG, A. (1963 b). Stabilization of various forms of Mycobacterium tuberculosis. Tubercle, London 44, 368-37I.

CsillaG, A. (1964a). Growth of form 2 mycobacterium and various Bacillus species on LoewensteinJensen medium. Journal of General Microbiology 34, 79-83.

Csillag, A. (1964b). The mycococcus form of mycobacteria. Journal of General Microbiology 34, $34 \mathrm{I}-352$.

Demikнovskir, I. E. (1961). The species composition of the bacterial antagonists of the oral cavity. Journal of Microbiology, Epidemiology and Immunobiology 32, I529-I533. (In Russian.)

Hilson, G. R. F. (1965). Taxonomic characteristics of so-called 'form 2 mycobacteria'. Journal of General Microbiology 39, 407-421.

Howard, D. H. (1962). The morphogenesis of the parasitic forms of dimorphic fungi. Mycopathologia and Mycologia Applicata 18, 127-139.

JuHASZ, S. E. (1962). Aberrant forms of Mycobacterium phlei produced by streptomycin and their multiplication on streptomycin-free media. Journal of General Microbiology 28, 9-1 3.

Kobayashi, G. S. \& Gulliacci, P. L. (1967). Cell wall studies of Histoplasma capsulatum. Sabouraudia 5, $180-188$.

KrassiLnikov, N. A. (1934). Die Entwicklungsgeschichte der Bodenmikrobakterien. Zentralblatt für Bakteriologie 9o, 428-434.

Krassilnikov, N. A. (1938). Microbiologia 7, part I, p. 335. (In Russian.)

Krassilnikov, N. A. (1959). Diagnostik der Bakterien und Actinomyceten, pp. 39, I30, 203, 204, 542, 555. Jena: Gustav Fischer.

LACK, C. H. \& TANNER, F. (1953). The significance of pleomorphism in Mycobacterium tuberculosis var. hominis. Journal of General Microbiology 8, I8-28.

Pease, P. (1970). An acid-fast bacillary phase in Streptococcus MG and certain other Gram-positive cocci: identification with Mycococcus (Krassilnikov). Journal of Medical Microbiology 3, 186I89.

Stewart-Tull, D. E. S. (1965). Occurrence of dimorphic forms of Mycobacterium phlei. Nature, London 208, 603-605.

TEPPER, B.S. (1965). Modification of cellular constituents during growth of Mycobacterium phlei. American Review of Respiratory Diseases 92, 75-82.

Topley and Wilson's Principles of Bacteriology and Immunity (1964), 5th edn, pp. 415, 536, IoI9. London: Edward Arnold.

Waksman, S. A. (1959). The Actinomycetes, p. 7I. London: Baillière, Tindall and Cox.

Waksman, S. A. (1961). The Actinomycetes, vol. 2, p. 33I. London: Baillière, Tindall and Cox.

XALABARDER, C. (1954). El origen del Bacilo de Koch, pp. 92, 94. Barcelona: Instituto Antituberculoso 'Francisco Moragas'.

Xalabarder, C. (1958). Electron microscopy of tubercle bacilli. Excerpta Medica II, 467. 